http://jmscr.igmpublication.org/home/ ISSN (e)-2347-176x ISSN (p) 2455-0450

crossref DOI: https://dx.doi.org/10.18535/jmscr/v8i3.27

Journal Of Medical Science And Clinical Research

\title{
Survey on post graduate medical education (Anaesthesiology) in India
}

\author{
Authors \\ Dr Subha. R, MD, DA ${ }^{1}$, Dr Rajasree. O, M.B.B.S, DNB (Anaesthesiology) ${ }^{2}$, \\ Dr Arya Sanjeev, MBBS, MD ${ }^{3}$, Dr Rachel Cherian Koshy, M.D, DA ${ }^{4}$, PDCC, \\ Dr Jagathnath Krishna K.M, PhD
}

${ }^{1}$ Associate Professor, Division of Anaesthesiology, Regional Cancer Centre, Thiruvananthapuram, Kerala, India

${ }^{2}$ Associate Professor, Division of Anaesthesiology, Regional Cancer Centre, Thiruvananthapuram, Kerala, India

${ }^{3}$ Senior Resident, Division of Anaesthesiology, Government Medical college, Thiruvananthapuram, Kerala, India

${ }^{4}$ Professor \& HOD, Division of Anaesthesiology, Regional Cancer Centre, Thiruvananthapuram, Kerala, India

${ }^{5}$ Assistant Professor, Division of Cancer Epidemiology \& Biostatistics, Regional Cancer Centre,

Thiruvananthapuram, Kerala, India

*Corresponding Author

Dr Subha. R, MD, DA

\begin{abstract}
Background and Aim: The product of the post graduate Anaesthesia training should be a competent specialist with good theoretical knowledge, practical, clinical, communication and research skills. Anaesthesia training poses various challenges which include providing meaningful educational experiences for residents, without compromising on safety and quality of patient care. Exponential growth in knowledge and technology needs to be incorporated in the curriculum. Learners should be assessed in a comprehensive manner by new assessment methods which require faculty training. This survey aims at assessing the facilities available in various postgraduate Anaesthesia training centres and recommending suggestions in the areas of deficiencies.
\end{abstract}

Methods: A questionnaire of 18 questions was distributed among a subgroup of Anaesthesiologists who attended a National Conference of Indian Society of Anaesthesiologists. The filled-in questionnaires were computed and analysed with SPSS version 11.

Results: Response rate of the survey was $75 \%$. Government sector outnumbered private sector by having more regular internal assessment and adequate library facility. Private sector had more number of interdepartmental classes, adequate faculty rooms, computers with internet facility and subscription of Indian and foreign journals. Regarding facilities, there was a comparative deficiency of cardiac output monitor and video laryngoscope. Simulation lab was available in only $20 \%$ institutions. Less number of respondents has undergone training in ultrasound, haemodynamic monitoring and research methodology compared to ACLS, intensive care, FOB use \& pain and palliative care.

Conclusion: Fast growing technological advances demand addition of certain elements in our current curriculum. Some recommendations are given in the article.

Keywords: Graduate medical education, Anaesthesiology, India, surveys and questionnaires.

\section{Introduction}

The medical education system in India is one of the largest in the world. ${ }^{[1]}$ It confronts a number of issues in general and Anaesthesiology in particular. They include faculty development, reforms in the curriculum, establishment of new 
medical colleges ,their accreditation and selection of students. ${ }^{[2]}$ To re-look at various aspects of medical education, training and practice in the country, Medical council of India developed a "Vision 2015" document, addressing the areas of graduate and postgraduate medical education including examination patterns, ethics of medical practice, equivalence of various degrees and courses, enhancement of remunerations for medical teachers and setting up standards for accreditation of medical colleges. ${ }^{[3]}$ As laid down by MCI the major components of the Postgraduate curriculum shall be ,theoretical knowledge, practical, clinical ,research and communication skills. ${ }^{[4]}$ The goal of postgraduate medical education shall be to produce competent specialists and/or Medical teachers who shall recognize the health needs of the community, carry out professional obligations ethically keeping with the objectives of the national health policy. ${ }^{[4]}$

\section{Methods}

Questionnaires on the Post graduate medical education in Anaesthesiology were distributed among 200 anaesthesiologists who visited a business promotion stall during the National Conference of Indian Society of Anaesthesiologists in 2016.The questionnaire was validated by collecting data from anaesthesiologists working in our centre. From the same group of anaesthesiologists, the same information was collected after 1 month. The difference between the survey responses at these time intervals was tested and found to have no significant difference. This validated the questionnaire and we found it to be reliable

The questionnaire contained eight questions with sub questions [Additional file 1] pertaining to the practice setting, number of post graduate seats per year, number of consultants, elective cases in OT per month, lectures by junior residents and faculty, case discussions, journal clubs, availability of equipments / facilities like Anaesthesia workstations, modern ICU ventilators, Cardiac output monitor, video laryngoscope, FOB, USG machine and simulation lab. Formal training if undergone in the following were asked : Research methodology, ACLS, intensive care, pain \& palliative service, haemodynamic monitoring, usage of equipments like FOB, adequate faculty and PG rooms, library with Indian and International journals, computers with internet facility, smart lecture halls. Questions were there in relation to interdepartmental classes, regular audit, monthly mortality meeting, daily ICU rounds, bed side (OT) classes by faculty, regular internal assessments. The participation was voluntary and the identity of the participants was kept confidential.

Survey responses were analysed using SPSS version 11.The categorical variables were represented using frequency and percentages. The continuous variables were represented using Mean and Standard Deviation. The continuous variables satisfying normality assumption, the significant difference between the groups were tested using Student's t-test. The comparison between the categorical variables was done using Chi-Square or Fisher's exact test p-value $<0.05$ was considered to be statistically significant.

\section{Results}

200 questionnaires were distributed to doctors and 162 questionnaires were returned. Of this 12 were excluded due to incomplete data. So the response rate is $75 \%$. Out of the 150 doctors who participated in the survey, 112 were consultant anaesthesiologists, 7 were senior resident anaesthesiologists and 31 were junior residents [Figure 1]. Among them, 109 doctors practised in a government setting whereas 41 worked in the private sector [Figure 2]. Out of the total 150 doctors, 54 were from south India, 53 from north, 21 from east and 22 from western part of India. Frequency of monthly departmental academic events is compiled in Table 1. Comparison of department facilities between the two practice settings was done with respect to 


\section{JMSCR Vol||08||Issue||03||Page 162-168||March}

interdepartmental classes, regular audit, monthly mortality meetings, daily ICU rounds, bedside class by faculty, regular internal assessment, adequate library facility, adequacy of faculty and PG rooms, lecture hall with projectors, computers with internet facility and subscription of Indian and foreign journals [Table 2]. Among these facilities, government sector outnumbered private sector by having more of regular internal assessment (p-0.0001) and adequate library facility (p-0.025). $100 \%$ of the government institutions had regular internal assessment whereas only $70.7 \%$ of the private institutions had regular internal assessment. Private sector had significantly more number of interdepartmental classes ( $\mathrm{p}-0.001)$, adequate faculty rooms ( $\mathrm{p}$ $0.0001)$, computers with internet facility ( $\mathrm{p}-0.023)$ and subscription of Indian ( $\mathrm{p}-0.0001)$ and foreign (p-0.0001) journals. There was no significant difference between the two practice settings with regard to regular audit, monthly mortality meetings, and daily ICU rounds, bedside class by faculty, adequate PG rooms or lecture hall with projectors. $100 \%$ of the doctors from the private sector opined that they had adequate faculty rooms and subscription to Indian journals.

With respect to equipment availability and training provided in institutions, only 30 consultants (20\%) reported the availability of simulation labs in their centres whereas modern ICU ventilators and Fibre optic bronchoscopes were available in $70(46.67 \%)$ and $80(53.33 \%)$ institutions respectively [Table 3]. ICU and ACLS training were provided in only $50 \%$ of the institutions and ultrasound training was provided in only $30 \%$ of institutions [Table 4].

Table 1 Frequency of academic events per month

\begin{tabular}{|lccc|}
\hline & $\mathbf{0}$ & $\mathbf{1 - 5}$ & $\mathbf{> 5}$ \\
\hline Lectures by junior residents & 24 & 125 & 1 \\
\hline Lectures by faculty & 5 & 145 & 0 \\
\hline Case discussions & 0 & 150 & 0 \\
\hline Journal clubs & 5 & 145 & 0 \\
\hline
\end{tabular}

Table 2 Facility in Medical Colleges

\begin{tabular}{|lccccc|}
\hline \multirow{2}{*}{ Facility } & Government (109) & \multicolumn{2}{c}{ Private (41) } & \multirow{2}{*}{ P value } \\
\hline Inter Departmental Classes & Present & Absent & Present & Absent & \\
\hline Regular Audit & 81 & 28 & 41 & 0 & $0.001^{*}$ \\
\hline Monthly Mortality Meet & 80 & 29 & 34 & 7 & 0.223 \\
\hline Daily ICU rounds & 89 & 20 & 28 & 13 & 0.078 \\
\hline Bedside class by faculty & 98 & 11 & 33 & 8 & 0.122 \\
\hline Regular Internal assessment & 93 & 16 & 36 & 5 & 0.696 \\
\hline Adequate library facility & 109 & 0 & 29 & 12 & $0.0001^{*}$ \\
\hline Adequate faculty rooms & 103 & 6 & 34 & 7 & $0.025^{*}$ \\
\hline Adequate PG rooms & 59 & 50 & 41 & 0 & $0.0001^{*}$ \\
\hline Lecture hall with projectors & 74 & 35 & 34 & 7 & 0.068 \\
\hline Computers with internet facility & 104 & 5 & 36 & 5 & 0.096 \\
\hline Indian Journals & 76 & 33 & 36 & 5 & $0.023^{*}$ \\
\hline Foreign Journals & 81 & 28 & 41 & 0 & $0.0001^{*}$ \\
\hline
\end{tabular}

Table 3 Availability of equipments

\begin{tabular}{|lcc|}
\hline Equipment & Number & \% \\
\hline Simulation lab & 30 & 20.00 \\
\hline Video laryngoscope & 55 & 36.67 \\
\hline Cardiac output monitor & 50 & 33.33 \\
\hline Modern ICU ventilator & 70 & 46.67 \\
\hline Anaesthesia work station & 65 & 43.33 \\
\hline USG & 65 & 43.33 \\
\hline FOB & 80 & 53.33 \\
\hline
\end{tabular}


Table 4 Training provided

\begin{tabular}{|lcc|}
\hline Training & Number & \% \\
\hline Pain \&palliative & 65 & 43.33 \\
\hline Research methodology & 55 & 36.67 \\
\hline Haemodynamic monitoring & 55 & 36.67 \\
\hline USG & 45 & 30.00 \\
\hline FOB & 60 & 40.00 \\
\hline ICU & 75 & 50.00 \\
\hline ACLS & 75 & 50.00 \\
\hline
\end{tabular}

\section{Discussion}

In the survey, less number of respondents had undergone training in ultrasound, hemodynamic monitoring and research methodology. So a critical issue in the post graduate medical education in India is faculty development. ${ }^{[1]}$ Good quality postgraduates can be produced only by well-trained faculty. The NTTC (National Teachers Training Centres) at JIPMER and Maulana Azad Medical College in New Delhi conducts programs for medical educators in areas of education objectives, curriculum design, teaching methods and assessment. The Foundation for Advancement of International Medical Education and Research (FAIMER) also supports faculty development in India. ${ }^{[1,5]}$ The faculty is also a role model for demonstrating how to work in team, get along with team mates , good communication skills to colleagues, patients and their families.

A second key challenge is the increasing number of medical colleges in India. ${ }^{[2]}$ The high demand for post graduation and high tuition fees may be the reason for the proliferation of large number of private medical colleges. The sudden growth of medical schools in the country has resulted in the increased need for medical teachers with vacant faculty positions in many colleges. This has also led to the misdistribution of resources. ${ }^{[2]}$

One of the general objectives of Post graduate training as suggested by MCI is to demonstrate empathy and humane approach towards patients, exhibit interpersonal behaviour in accordance with societal norms and expectations. ${ }^{[4]}$ This questions the validity of selecting students solely on the basis of a single multiple choice examination. ${ }^{[2,6]}$
There should be an aptitude test to select candidates for both under-graduate and postgraduate medical education. As suggested by MCI Vision 2015, the algorithm of selection of post graduate medical students is as follows: Ranking for PG course shall be based on a common exit examination conducted after Third Professional MBBS Degree Examination followed by a licentiate examination after internship to assess the skills and competence of the candidates. ${ }^{[3]}$ With new proposed changes, candidate would be free to concentrate on skill development during internship. This suggestion will certainly improve the quality of post graduate medical education.

Recently the Union Cabinet approved certain official amendments to the National Medical Commission (NMC) Bill. The Amendments include:

Final MBBS examination to be held as a common exam across the country and would serve as an exit test called the National Exit Test (NEXT). Thus the students would not have to appear in a separate exam after MBBS to get license to practice. NEXT would also serve as the screening test for doctors with foreign medical qualifications in order to practice in India. The maximum limit of $40 \%$ seats for which fee would be regulated in private medical institutions and deemed universities has been increased to $50 \%$.Further; it has been clarified that the fee would also include all other charges taken by the colleges.

MCI requires that the medical faculty engages in research. ${ }^{[7,8]}$ Among the criteria used for promotions, publication of research is an essential requirement. ${ }^{[7]}$ Though the need for this is debated, it is believed that quality of teaching 
improves when teachers are involved in research. ${ }^{[7,9]}$

It is also necessary to provide academic recognition to teachers for their contribution to teaching. Otherwise, teaching will be overtaken by the priorities of research and patient care. ${ }^{[1]}$ it is important to encourage and reward teachers who show a flair for teaching and adopt innovative teaching methods. ${ }^{[1,6]}$ Teaching is not everybody's cup of tea. Teaching requires aptitude, constant updating and meticulous preparation to do a good job. In the west, residents assess and give feedback about faculty on a regular basis. It is not only didactic teaching, but also clinical teaching skills which require patience and it involves risk taking; as far as patient is concerned. The resident does not have medico legal responsibility. The faculty has vicarious liability for complications produced by the resident in the process of learning.

Students and doctors who engage in teaching and research should have appropriate teaching and learning resources, such as libraries, computing equipment and teaching rooms. These resources should be regularly reviewed and assessed. Effective medical education and good quality research need time to do so. Those responsible for programmes should make appropriate arrangements for protected time to be set aside for them.

In an era when information is available at finger tips on mobile phone, I-pad one may doubt about the relevance of adequate library facility. But the fact is that authentic, current and relevant organised information is available only from libraries. Only very few indexed, peer reviewed journals provide open access. Majority of journals and data bases can be accessed only through a subscription which is facilitated by a library of the concerned institution. In addition to providing materials, libraries also provide services of librarians who are experts at finding, organizing and interpreting information needs. Modern libraries are increasingly being redefined as places to get unrestricted access to information in many formats and from many sources. They are extending services beyond the physical walls of a building by providing materials accessible by electronic means, and by providing the assistance of librarians in navigating and analysing very large amounts of information with a variety of digital tools.

Clinicians confronted with information overload, are finding it very difficult to choose or locate the right information at the right time in an efficient manner. The availability and accessibility of accurate and credible information is essential for decision making. Lack of availability and difficulty in the timely access of biomedical information sources prevent the rendering of better health care services. The expanding number of journals, original research articles, review articles, books, various types of online databases - both free and paid has resulted in exponential growth of multilingual literature in this discipline. As the rate of change in medical knowledge increases, coping with the information overload is a major challenge in all branches of medicine. For a health care system to excel in all aspects, it should be supported by a well organized Library and Information System. The basic purpose of an information system is to provide the individual or institution the information required for decision making.

Adult learning has various nuances. See one, assist one, do one for practical skills. Regarding simulation based learning it is aptly said; "Tell me and I forget, show me, and I remember, let me do and I understand. Simulation can provide the opportunity for deliberate practise to attain excellence in a safe environment. It can also be used for team training.

Use of technology in Anaesthesia education like E-learning, Wikis and podcasts will increase in future. ${ }^{[10]}$ Training in echocardiography and ultrasound in the intensive care setting is essential. Difficult airway gadgets usage should be familiarized. Training in areas of research methodology, ACLS, pain and palliation should be made compulsory for the residents. 
Suggestions were asked to the respondents to improve post graduate teaching.

Those were, to improve bed side teaching, improve library facilities, free internet access, access to journals, training facilities in various procedures and equipments, to limit resident duty hours to a maximum of $24 \mathrm{hrs}$, to give emphasis on simulation based teaching.

The recommendations suggested in the survey responses are given below.

Recommendations ${ }^{[2,3,10]}$

1) Greater focus should be given to bed side teaching

2) Objective structured practical and clinical examinations should be added to the current theory/ multiple choice based assessment

3) Formative student assessment should be added to the current summative assessments.

4) Simulation labs/skill labs should be set up for skill oriented training with efficient supervision and assessment

5) Faculty and students must undergo training in research methodology

6) Selection to post graduate training should include an aptitude test too in addition to the current multiple choice test.

7) More interdepartmental discussions, regular audit, monthly mortality morbidity meetings to be conducted.

8) Adequate library facility with internet access with subscription to print and ejournals should be provided to faculty and residents.

9) Adequate faculty and resident rooms should be provided

In conclusion we would like to comment that in the era of fast growing technological advances, certain elements needs to be added to our current curriculum. Anaesthesia departments should fight to get more facilities for providing high quality care and good teaching .Getting additional equipments is often dependent on the potential muscle power of a particular department. There is no need to compromise or play second fiddle. We deserve the best and should certainly persuade administrators to procure for us.

\section{References}

1. Bhatnagar K, Srivastava K, Singh A. Is faculty development critical to enhance teaching effectiveness? Industrial psychiatry journal. $2010 \mathrm{Jul} ; 19(2): 138$.

2. Supe A, Burdick WP. Challenges and issues in medical education in India. Academic Medicine. 2006 Dec 1; 81(12):1076-80.

3. Reforms in under-graduate and postgraduate medical education, Vision 2015: Medical Council of India.

4. Medical council of India postgraduate medical education regulations, 2000

5. Norcini JJ, Burdick WP, Morahan PS. The FAIMER Institute: creating international network of medical educators. Med Educ. 2005;27:214-218.

6. Sood R, Adkoli BV. Medical education in India-problems and prospects. $\mathbf{J}$ Indian Acad Clin Med. 2000 Oct; 1(3):210-2.

7. Aggarwal R, Gogtay N, Kumar R, Sahni P. The revised guidelines of the Medical Council of India for academic promotions: Need for a rethink.

8. Sukhlecha A. Research publications: Should they be mandatory for promotion of medical teachers? J Pharmacol Pharmacother. 2011;2:221-4

9. Rosenberg L. Physician-scientistsendangered and essential. Science 1999;283:331-2.

10. Pardo M Jr, Schell RM. Teaching Anaesthesia. In: Miller RD ed. Miller's Anaesthesia. $8^{\text {th }}$ ed. Philadelphia: Elsevier, 2015. P. 210-31

11. Foundation for Advancement of International Medical Education and Research International Medical Education Directory. Available from: http://www.imed.ecfmg.org/. 
12. Boyer EL. Scholarship Reconsidered: Priorities of the Professoriate. Princeton Publishers: Carnegie Foundation for the Advancement of Teaching. 1990.

13. Cole KA, Barker LR, Kolodner K, Williamson P, Wright SM, Kern DE. Faculty development in teaching skills: An intensive longitudinal model. Acad Med 2004;79:469-80.

14. Majumder MA, D’Souza U, Rahman S. Trends in medical education: challenges and directions for need-based reforms of medical training in South-East Asia. Indian J Med Sci.2004;58:369-380.

15. Baldwin C, Chandran L, Gusic M. Guidelines for evaluating the educational performance of medical school faculty: primimg a national conversation. Teach Learn Med.2011;23:285-97. 